\title{
TQM-ING OMB: OR WHY REGULATORY REVIEW UNDER EXECUTIVE ORDER 12,291 WORKS POORLY AND WHAT PRESIDENT CLINTON SHOULD DO ABOUT IT
}

\author{
E. DONALD ElliotT*
}

INTRODUCTION

No feature of modern U.S. government has been more controversial over the last decade than review of agency rules by the Office of Information and Regulatory Affairs of the Office of Management and Budget ("OMB") and other parts of the Executive Office of the President. ${ }^{1}$ And yet, despite all the controversy, no president, not Bill Clinton ${ }^{2}$ and probably not even Ross Perot, would dream of abolishing review of agency actions by the OMB, or some other entity in the Executive branch. Indeed, on October 4, 1993, after this article was presented, President Clinton signed an Executive Order revising the OMB regulatory planning and review process, ${ }^{3}$ and incorporating some of the suggestions made in this article. ${ }^{4}$ Clark Clifford explains: "If a President did

\section{Copyright 1994 by Law and Contemporary Problems}

* Formerly, Assistant Administrator and General Counsel, Environmental Protection Agency, 1989-91. Senior partner and head of Washington Environmental Department, Fried, Frank, Harris, Shriver and Jacobson, New York and Washington, D.C.; Julien and Virginia Cornell Professor of Environmental Law and Litigation, Yale Law School (on leave of absence, 1993-94).

1. During the Bush Administration, the OMB served as a clearinghouse, collecting comments from other agencies, members of the White House staff, and other entities within the Executive Branch, and transmitting them to the EPA. In the balance of this article, references to the OMB also refer to comments originating elsewhere in the Executive Branch and passed through the OMB.

2. Bill Clinton and Administrative Law, 18 ADMIN. L. NEws 1 (1992) ("[T]he Clinton administration would retain those features of [Executive Order 12,291] that further rational and coordinated decisionmaking, but ... would modify them to make the process open and to give appropriate weight to environmental, health, and safety issues, as well as economic issues.").

3. Exec. Order 12,866 ("Regulatory Planning and Review"), 58 FED. REg. 51735 (1993).

4. For example, the new Clinton Executive Order emphasizes identifying potential conflicts "at an early stage" and convening annual "policy meetings" with agency heads to "seek a common understanding of priorities." Id. at 51738, \& 4. Compare infra text accompanying notes 28-38 (on importance of developing a shared sense of mission between the OMB and the agencies). The principal drafter of the new Clinton Executive Order, Sally Katzen, Administrator of the Office of Information and Regulatory Affairs, reviewed a draft version of this article while the new executive order was being drafted. See also Al Gore, Improving Regulatory Systems: Accompanying Report of the National Performance Review 13 n.23 (Washington, D.C., September 1993) (citing the present article with approval). In addition, the author served on the task force that prepared the Carnegie Commission 
not control the bureaucracy, the bureaucracy would control him."5 OMB review is like God: if it did not exist, we would need to invent it.

Between 1989 and 1991, I found myself, as General Counsel of the Environmental Protection Agency, on the front lines in perhaps the most contentious and troubled relationship between the OMB and the agencies. This article contains my reflections on what I saw and my thoughts on how the new Administration should improve this necessary, but deeply troubled, relationship.

II

\section{WHAT THE REGULATORY REVIEW CONTROVERSY OBSCURES}

Most of the criticism of OMB review of EPA rules has fallen into two categories: (1) that the OMB constitutes a secretive back-channel by which groups with special access to the White House can express their views off the public record, ${ }^{6}$ and (2) that the emphasis on economics and cost/benefit analysis in Executive Order 12,291 is inconsistent with mandates in the environmental statutes. $^{7}$ Both of these criticisms raise important issues, and, for that reason, I wish to make my position on them clear.

As does the Administrative Conference, I believe that communications by interested parties (such as industry) to the OMB and the White House staff that provide significant factual information should be documented and placed in the public record. ${ }^{8}$ In addition, if important policy issues are raised by the OMB or other agencies during Executive Office review, either orally or in writing, as a prudential matter the nature and substance of the concerns raised should be made available to the public at an appropriate time, probably after deliberations

report suggesting revisions to the OMB review process, Carnegie Commission on Science, Technology and Government, Risk and the Environment: Improving Regulatory Decisionmaking 48-52, 112 (Washington, D.C., June 1993). The Carnegie Commission report was also considered by the Administration in developing Exec. Order 12,866.

5. Clark Clifford \& Richard Holbrooke, Counsel to THE PRESIdent: A Memoir 325 (1991). See also Lloyd N. Cutler \& David R. Johnson, Regulation and the Political Process, 84 YALE L.J. 1395 (1975) (central coordinating mechanism needed to harmonize policymaking by "single mission agencies").

6. See, e.g. Erik O. Olson, The Quiet Shift of Power: Office of Management \& Budget Supervision of Environmental Protection Agency Rulemaking Under Executive Order 12,291, 4 VA. J. NAT. RESOURCES L. 1, 40-73 (1984); Robert V. Percival, Checks Without Balance: Executive Office Oversight of the Environmental Protection Agency, 54 LAw \& CoNTEMP. PRoBs. 127, 151 (Autumn 1991) ("Congressional oversight hearings lent credence to charges that the OMB had served as a vehicle for secret, back door lobbying by industry during the Reagan Administration."); Id. at 165-72 (secrecy in the rulemaking process). See also Paul R. Verkuil, Jawboning Administrative Agencies: Ex Parte Contacts By the White House, 80 CoLUM. L. REV. 943 (1980).

7. Percival, supra note 6, at 168 ("Decisions reached at the behest of Executive Office reviewers are likely to be more vulnerable to judicial challenge than are other regulations because regulatory review usually emphasizes different factors than do the statutes and the administrative record."). See also ThOMAs O. MCGARITY, REINVENTING RATIONALITY: THE Role OF REgulatORY ANALYSIS IN THE FEDERAL BUREAUCRACY 1-16 (1991) (describing "clash of rulemaking cultures" between the OMB and agencies).

8. Intragovernmental Communications in Informal Rulemaking Proceedings (Recommendation No. 80-6), 1 C.F.R. $\$ 305.80-6$ (1993). 
within the Executive Branch are completed.9 Excessive secrecy undermines public confidence in the policy process and is not truly necessary to assure full and frank discussion of options.

On the other hand, in my experience, economic analysis by the OMB generally improves, as well as delays, the EPA rules. ${ }^{10}$ Indeed, many (perhaps as much as eighty percent) of the major issues raised by the OMB had not previously received substantial consideration in internal EPA deliberations. On one hand, this is encouraging, in that it suggests that the OMB process is adding value. On the other hand, it is also deeply disturbing, because fundamental issues are raised very late in the process, when it is virtually impossible to do anything productive about them.

While the OMB frequently raises fundamental questions about how to improve the agency's proposed approach to regulation, the OMB does not override statutory mandates. The "constitution" of OMB review, Executive Order $12291,{ }^{11}$ specifically provides that the OMB may not disregard statutory requirements ${ }^{12}$ and may only review exercises of discretion by agencies. In my experience, when agencies persuade the $\mathrm{OMB}$ and the White House that provisions of their rules are truly required by statute, they have no difficulty passing OMB review, even if the rules clearly would not pass muster under the cost/benefit analysis of Executive Order 12,291.

Whether one thinks that the OMB process "frustrates statutory intent" depends upon how commodious a view one adopts of the Executive Branch's authority to interpret statutes in the wake of the Chevron decision, ${ }^{13}$ and even more upon one's view of the extent to which legislative history (particularly floor statements and committee reports of a single house) are regarded as binding. ${ }^{14}$ Much of the rhetoric about the OMB frustrating the intent of statutes is really an objection to recent Supreme Court decisions that have transferred power to construe ambiguous statutes from the lower courts and congressional staff to the Executive Branch.

9. But see Presidential Review of Agency Rulemaking (Recommendation No. 88-9), 1 C.F.R. $\S$ 305.88-9 (1993) (distinguishing between oral and written policy guidance); Wolfe v. Department of Health \& Human Serv., 839 F.2d 768 (D.C. Cir. 1988) (en banc) (holding that records showing status of rules pending at the OMB are exempt from disclosure under the Freedom of Information Act).

10. See generally Stephen Breyer, Agency Autonomy and the Unitary Executive, 68 WASH. U. L. Q. 495 (1990) (panel discussion among Judge Stephen Breyer, Professor E. Donald Elliott, Judge Laurence Silberman, and former Justice Department official Terry Eastland, at Federalist Society Conference, "The President and Congress: Constitutionally Separated and Shared Powers," Washington, D.C., Jan. 19-20, 1990).

11. Exec. Order No. 12,291, 3 C.F.R. $\$ 127$ (1981), reprinted in 5 U.S.C. $\$ 601$ (1988).

12. Id. $\$ 2$ ("to the extent permitted by law"). See also Larry L. Simms, Acting Assistant Attorney General, Off. Legal Counsel, Memorandum Re: Proposed Executive Order Entitled "Federal Regulation," February 13, 1981, reprinted in REgulatORY PROGRAM OF THE UNITED STATES GOVERNMENT APR. 1, 1990-MAR. 31, 1991, at 608, 612 (1990) (Attachment A to App. III).

13. Chevron v. Natural Resources Defense Council, Inc., 467 U.S. 837 (1984).

14. Brock v. Pierce County, 476 U.S. 253, 263 (1986) (holding that floor statements should be considered but are not controlling). 
While these two issues-public oversight and the rise of regulatory analysis drawn from economics-are important, they have monopolized public debate about the OMB process to the exclusion of other important issues. It is these unexplored management issues that I address in the balance of this article. The essence of my complaint is not that the OMB is too powerful, but that because the regulatory review process is poorly designed, review does not effectively achieve its stated goals.

Although the entity that conducts regulatory review is part of the Office of Management and Budget, the review process itself violates virtually every tenet of good management-probably because it was designed by lawyers. ${ }^{15}$ The point is not a personal one, and in fact not all the designers of Executive Order 12,291 were lawyers. The point is rather that the basic modalities of review under Executive Order 12,291 were drawn, perhaps unconsciously, from appellate court review of agency rules. ${ }^{16}$ Episodic judicial review of agency decisions has not proved to be the most effective way of reshaping government policy. As a management style, when the OMB borrows these techniques, it suffers from many of the same deficiencies. In fairness, however, the OMB regulatory review process probably has proved superior to the courts in articulating clear principles of decision such as costlbenefit analysis. Chris DeMuth, one of the principal drafters of Executive Order 12,291 and the first Head of the Office of Information and Regulatory Affairs ("OIRA"), recently stated that these principles were "the most important part" of Executive Order 12,291. ${ }^{17}$

This article looks at the regulatory review process from a management perspective and suggests improvements. As the title of this symposium suggests, one can view the regulatory review process as a regulatory system on a meta level, "regulating the regulators." As a meta-regulator, the present system violates virtually all that we know about how to design effective regulatory systems. To be effective, a system of regulation must create compliance incentives for regulated parties, rather than rely on corrective action and oversight.

Part III of this article illustrates some of the recurrent problems of the present design of the regulatory review system with a hypothetical case drawn

15. For a general discussion of the OMB review process by two of its designers, see Christopher C. DeMuth \& Douglas H. Ginsburg, White House Review of Agency Rulemaking, 99 HARV. L. REV. 1075 (1986).

16. Christopher C. DeMuth, Regulatory Policy in the Reagan Administration, in AMERICAN ECONOMICS POLICY IN THE 1980's, 504, 505 (Martin Feldstein ed., 1993) (drawing analogy to "common law of review of individual rules").

17. Personal communication, American Enterprise Political Economy Roundtable, Feb. 17, 1994. Elsewhere, the present author has expressed some concern with the tendency of the new Clinton Executive Order to obscure these clear principles by making many values equally paramount. See $\mathrm{E}$. Donald Elliott \& Alan B. Horowitz, Risk-Based Environmental Priorities: What Priority?, in WATER Resources Regulation: Where is the Environmental Pendulum Now?, Conference Proceedings (1993) (criticizing Exec. Order 12,866 on grounds that "[i]f every thing is a priority, then nothing is a priority"). 
from my experiences as the EPA General Counsel. ${ }^{18}$ Part IV uses some of the principles of Total Quality Management ("TQM"), a management philosophy developed by Dr. W. Edwards Deming, to criticize the OMB regulatory review process. The final section of this article offers practical suggestions for implementing some of the principles of TQM and redesigning the way that regulatory review operates.

Of course, no application of TQM or any other management principles to redesign the regulatory review process is a panacea that would sweep away all conflict between the OMB and the agencies whose rules it regulates and reviews. On the contrary, as others have shown, and my own experience confirms, many of the conflicts between the OMB and the EPA involve basic issues of public policy, and derive ultimately from fundamental differences in the weight to be accorded to competing values. ${ }^{19}$ Some policymakers value economic efficiency more than others, whose primary concern is reducing risk to human health and the environment. To some degree, then, conflict along the OMB-EPA fault-line is healthy and, in any event, inevitable. It is not, however, irreducible; thus it is the goal of this article to focus attention on the unnecessary inefficiencies in the OMB review process, not the inevitable frictions and delays.

To a surprising degree, the current guerilla warfare between the OMB and the EPA over the content of rules is neither necessary nor an inevitable outgrowth of core differences in values. The unnecessary conflict and inefficiency result in part from a defective process in which the actors do not understand each other's goals and objectives, do not share a common definition of the enterprise, and have become locked into fixed positions from which retreat or compromise is difficult. In many instances, mutually destructive delays and confrontations in the Bush Administration could have been avoided if the process had been designed to facilitate a more collaborative, less confrontational decisionmaking process.

\section{III}

\section{The IMAGinaRY OMB ReviEw of THE EPA's PHLOGISTON RULE ${ }^{20}$}

Roughly eighteen months before sending the draft Phlogiston rule to the $\mathrm{OMB}$, the EPA submitted a regulatory agenda to the OMB under Executive Order 12,498, identified Phlogiston as a substance that it intended to regulate, and estimated the cost at $\$ 100$ million per year. The EPA's submission

18. For examples of other scholars who have adapted the roman a clef technique to discuss their experiences in government, see Douglas M. Costle, Brave New Chemical: The Future Regulatory History of Phlogiston, 33 ADMIN. L. REV. 195 (1981); Judith Resnik, Managerial Judges, 96 HARV. L. REV. 376 (1982).

19. See MCGARITY, supra note 7, at 5-16.

20. The hypothetical does not represent a single, actual case, but is instead a composite of my experiences in government, every feature of it having occurred during my tenure at the EPA. Many of the more troubling features of the process illustrated by the hypothetical are also well documented in other published case studies. See, e.g., JOHN QUARLES, ClEANING UP AMERICA: AN INSIDER's VIEW of the EnVIRonmental Protection AgenCy (1976). 
contained the standard boilerplate language that its consideration of Phlogiston had not yet progressed to the point at which it could identify particular options or consider alternatives, and noted a statutorily mandated due date for the final rule. At the time of this submission to the OMB, the EPA staff was already actively considering three control options-flaring technology, process modifications, and catalytic technology-and gathering data about the efficacy and cost of each. The EPA justified its failure to share this information with the OMB on the grounds that the options had not yet been approved by EPA management, and hence did not represent a formal agency decision, but rather the staff's decision of areas in which to gather information.

The OMB spent virtually no time reviewing the preliminary EPA submission, noting only that the significant $\$ 100$ million cost estimate for Phlogiston would justify some attention later. In particular, the OMB did not delve beyond the EPA's bland assurance that no options had been identified, did not focus on the statutory requirements, and did not suggest creative approaches for the agency to consider.

A few weeks later, EPA Deputy Administrator and the General Counsel and Assistant Administrator for its Office of Policy, Planning and Evaluation met informally with the Acting Head of OIRA and the Branch Chief for the Natural Resources Section of the OMB (who is in charge of review of all EPA rules). At this meeting, the OMB representatives mentioned the upcoming Phlogiston rule and expressed concern about its cost. The EPA's Deputy Administrator noted their concern and assured them that he would review the matter in a week or two, when he received a preliminary briefing on the status of the Phlogiston rule.

The next stage in the process was "options selection," a briefing for the Deputy Administrator by the workgroup at which they identified the options under consideration and received preliminary guidance from the Agency's management. No OMB representatives were present. After a thorough briefing of the three technologies being considered-flaring technology, process modifications, and catalytic technology-the Deputy Administrator stated that he was concerned about the potential costs of the rule, and requested that the staff consider innovative options, including incentive-based approaches along the lines of those being undertaken by other programs. The OMB was not mentioned.

At the next meeting of the workgroup, the staff lawyer from the General Counsel's Office informed the other members that an incentive-based approach would be illegal under the statute that applied to Phlogiston. The work group nevertheless decided to include a study of an incentive-based approach, as requested by the Deputy Administrator.

After several months, the workgroup briefed the Assistant Administrator for the program within the EPA with regulatory authority over Phlogiston (the "lead office"). She accepted the staff's recommendation to propose a technology-based standard based on catalytic technology. This option was characterized as the most cost-effective way to prevent pollution because of the resources that could 
be recovered, even though its direct costs were higher than flaring. Again, no OMB representatives were present, and at the time the political appointee responsible for the office regulating Phlogiston made her decision, she did not have the benefit of any input from the OMB.

Next, the draft of the proposed rule and supporting material were circulated for "red border" review to the other EPA offices for concurrence and comment. Based on those comments, changes were made and the lead office Assistant Administrator presented the matter for decision to the Deputy Administrator (who was delegated authority to make the agency decision on this rule from the Administrator). Again, the OMB did not receive copies of any of these materials. Thus, when the Deputy Administrator made a decision on behalf of the agency, he had no input from the OMB, other than their initial, informal expression of concern. There had been no contact between the EPA staff responsible for drafting the rule and the OMB staff responsible for reviewing it.

As expected, the Deputy Administrator followed the recommendation of the lead office Assistant Administrator, and opted for the middle option of the three presented to him, choosing neither the most nor the least expensive. ${ }^{21} \mathrm{He}$ then forwarded his decision, with supporting materials, including the Regulatory Impact Analysis ("RIA"), ${ }^{22}$ to the OMB for review under Executive Order 12,291 as the EPA's proposed rule. Thus, when the OMB staff first received the details about the Phlogiston rule, the EPA was already fully committed. That is, the EPA staff and all of the EPA political appointees had made a decision publicly, and the OMB analysis required by Executive Order 12,291 took place after the decision by the EPA.

The OMB was not pleased. The RIA, which none of the EPA political appointees had even seen, showed costs of approximately $\$ 300$ million per statistical life saved, well above the average for recent EPA rules (another fact that the political appointees at the EPA did not know). In addition, the OMB reviewer assigned to do most of the work (typically, a recent business or other professional school graduate) believed that the federal government had no business regulating Phlogiston at all and that the area should be left to the state and private industry. He had never been briefed on the statutory mandate under which the EPA was required to regulate Phlogiston.

The initial meeting between the OMB staff and the EPA representatives on the proposed rule made little progress. The OMB expressed its typical concern - that the rule was too expensive. The EPA responded in its typical way-that the statute required it to do what it was doing.

After several unproductive meetings, which became quite heated on a personal level, the issues were "elevated" to the political level. Meanwhile, the

21. For a discussion of the professional ethos and incentives that affect senior federal managers, see ROBERT A. KATZMAN, REgULATORY BUREAUCRACY (1980).

22. The RIA is the written analysis that agencies must compile as the basis for review of their major rules. See Exec. Order No. 12,291, 3 C.F.R. $\$ 127$ (1981), reprinted in 5 U.S.C. $\$ 601$ (1988); Exec. Order 12,866, 58 Fed. Reg. 51,735 (1993). 
Acting Director of OIRA received a letter from the Chair of the House oversight subcommittee which demanded an explanation for the delay of the Phlogiston rule, and threatened hearings. The OMB suspected that the EPA had inspired the congressional inquiry.

Next, the Head of OIRA, the OIRA branch chief, and the OIRA reviewer assigned to the case met with the EPA Deputy Administrator and the lead office Assistant Administrator. The professional EPA staff was not represented, which led them to suspect that the results of the meeting had been the result of wholly political considerations. After the OMB outlined a few minor issues on which progress had been made, the OMB representatives stated that the rule was too expensive, and that the OMB would not approve it in its present form. The OMB also expressed concern that the rule was not consistent with the Administration's federalism policy (an issue that had not been vetted at the EPA), and asked whether regulating Phlogiston could be left to the states. The OMB also proposed the possibility of a trading system, in which Phlogiston credits could be marketed and sold.

The Deputy Administrator assured the OMB that he was personally sympathetic to these concerns and had been working to implement them at the EPA. He noted, however, that it was too late to begin a fundamental rethinking of the Phlogiston rule along these lines, since none of the necessary data had been gathered and since a statutory deadline loomed. He also expressed concern that Congress and environmentalists would portray further EPA delay as a sign that the Administration was not seriously committed to its professed position of cleaning up the environment. He also pointed out that the proposed federal Phlogiston rule was less expensive for industry than some of the more extreme state regulations.

After several similar meetings, increasing public and congressional pressure forced a compromise: the EPA would modify its technology-based approach to exempt several categories of low volume-high cost sources (thereby bringing down the costs) and would propose for comment in the Federal Register as an option the OMB's suggestion that the whole area be left to regulation by the states. $^{23}$

23. The EPA General Counsel's office was firmly of the view that this approach was not legal under the statute. A closely related approach, "challenge regulation," in which the EPA sets standards for permissible state regulation, probably would be legal. This alternative was never mentioned to the OMB. 
IV

\section{Basic Principles of Total QualtTy MANAGEMENT ${ }^{24}$}

\section{A. The Flaw Is In the System}

Training in TQM often begins with the Parable of the Red Beads. ${ }^{25}$ Teams of six workers are formed and given the task of removing and separating red and white beads from a large tank. Red beads represent defects, while the white beads represent products that the customer wants. Teams usually consist of three workers, a foreman, an inspector, and a top manager.

"Management" gives the "workers" a paddle with a series of indentations and instructs them to use it to remove the white beads, while leaving the red beads behind. The inspectors then remove by hand any extra red beads that have been lifted out of the tank. With Dr. Deming keeping careful count of the results, the experiment begins.

Some "workers" do better than others at removing white beads with the paddles, but nobody is particularly successful. Lots of red beads come up with each scoop of the paddle and have to be removed by the "inspectors." Nothing that the "managers" try improves the "workers" performance much: not competing with other teams; not dictating precise operating procedures; not setting quotas for how many white beads will be produced by each scoop of the paddle; not paying incentive compensation to those workers who produce more white beads than average; not firing those whose performance is sub-par; not studying the techniques used by those who are best; not exhorting the "workers;"

24. Although a U.S. citizen, Dr. Deming's ideas were originally adopted by the Japanese, who credit him for much of their recent economic success. More recently, U.S. companies have begun adopting TQM with many extraordinary results. See, e.g., Doing It For Mother Earth, Bus. WK., Oct. 25, 1991, at 44 (describing efforts by companies such as Xerox, Proctor \& Gamble, Allied-Signal, and IBM to use TQM to "cut pollution and improve compliance, often while lowering their environmental costs"); Qualtiy Environmental Management Subcommittee of THE President's Commission ON Environmental Quality, Total Quality Management: A Framework for Pollution PREVENTION (1993).

While Dr. Deming's ideas provide a convenient beginning for analyzing problems in the current regulatory review process, one need not fully adopt the principles of TQM to understand the organizational problems with the process. To some extent, TQM consists of common sense applied to the design of systems and organizations. The key move for understanding what is wrong with the present OMB regulatory review process consists of thinking about OMB review as a management or regulatory system, and re-designing that system to be more effective than case-by-case, after-the-fact review. Numerous books, articles, lectures, and even a PBS television program are now available about Dr. Deming's "Total Quality Management" philosophy. For convenience, I have used two readily available sources for citations, RAPHAEl Aguayo, DR. DEMING: THE AMERICAN Who TAUght THE JAPANESE

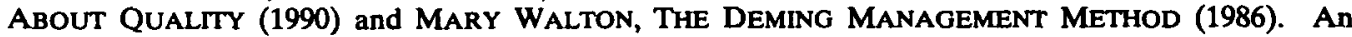
excellent summary of Deming's life and an introduction of his ideas can also be found in his recent obituary. John Holusha, W. Edwards Deming, Expert on Business Management, Dies at 93, N.Y. TIMES, Dec. 21,1993 , at B7, cols. $1-4$.

I want to pay special thanks to F. Henry Habicht, Deputy Administrator of the EPA, 1989-92, who first introduced me to Dr. Deming's ideas.

25. AGUAYO, supra note 24 , at 53-64; WALTON, supra note 24 , at $40-51$. 
not threatening the "workers;" and not adding more resources. None of these conventional management strategies improves the average worker's performance.

Finally, frustrated at their inability to improve the results, the group is encouraged to step back to reflect on the problem. At that point, Dr. Deming observes that while there is a great deal of statistical variability among workers, the paddles show remarkable consistency in their average efficiency in removing white beads. Prodded by this hint, the group begins to realize that the red beads and the white beads are of slightly different sizes, because the red beads have been made by dipping white beads into paint. If a paddle is made carefully, with holes just large enough to accommodate the white beads, it will easily scoop out many more white beads, while leaving almost all of the red beads behind.

The Parable of the Red Beads is designed to make several points, the most important of which for our purposes is that "[w]orkers work within a system that - try as they might-is beyond their control. It is the system, not their individual skills, that determines how they perform."26

Unenlightened managers frequently blame individual "bad" workers for problems in the system that are beyond the control of the workers; real progress is possible only by improving the system. It is ultimately the responsibility of managers to improve the design of the system-or perhaps better said, to create the conditions in which those who understand the system better than the managers are motivated and empowered to improve the system continuously.

Similarly, in most administrations, after a few years, the OMB and White House "managers" generally come to hold in contempt their erstwhile colleagues in the agencies, believing that they have "gone native" and adopted the characteristic values of their agencies. Like the managers in the Parable of the Red Beads, political managers in the White House and the OMB tend to blame the individual "workers" (that is, political appointees) in the agencies, rather than transforming the system so that they can produce more effectively.

Statistics similar to Dr. Deming's can be compiled to test the cost-effectiveness of the present OMB review process under Executive Order 12,291. An analysis by economist Kip Viscusi shows that the OMB is remarkably unsuccessful at holding down the costs of EPA rules. The OMB blocked only those proposed rules whose cost exceeded $\$ 142$ million per statistical life saved. ${ }^{27}$ While the OMB is sometimes marginally successful in making rules less expensive than they otherwise would have been, the hypothetical case of Phlogiston discussed above reveals that the OMB review process rarely succeeds in stimulating the EPA or other agencies to rethink their regulations in any fundamental way.

26. WALTON, supra note 24 , at 51 .

27. W. KIP VISCUSI, FATAL TRADEOFFs: PUBliC AND PRIVATE ResPonsibILITIES FOR RISK 265 (1992) ("[T]he minimum tradeoff threshold for the OMB to reject a regulation is quite high. None of the [30 EPA-OSHA-CPSC-FAA rules studied 1980-1989] with costs per life saved below \$142 million were rejected. The OMB's efficacy is apparently limited to the more extreme instance of regulatory excess."). 
While observers may differ over whether $\$ 142$ million per statistical life saved is a desirable, cost-effective level of risk reduction, ${ }^{28}$ Viscusi's statistics do give some indication of the approximate average level of performance to be expected over time from the current system of the OMB's case-by-case review of rules under Executive Order 12,291. As in the Parable of the Red Beads, substantial improvement in the process will come neither from blaming the workers nor from motivating them to work harder; there must be changes in the system before the process will improve.

B. The Fallacy of Quality by Inspection

A second, fundamental principal of TQM is that quality cannot be "inspected into" a product:

\begin{abstract}
"Inspection with the aim of finding the bad ones and throwing them out is too late, ineffective, costly," says Dr. Deming. "In the first place, you can't find the bad ones, not all of them. Second, it costs too much." The result of such inspection is scrap, down-grading and rework, which are expensive, ineffective and do not improve the process. "Quality comes not from inspection but from improvement of the process."
\end{abstract}

"The old way: Inspect bad quality out."

"The new way: Build good quality in."29

The basic philosophy underlying the concept of case-by-case regulatory review is improving quality through inspections at the end of the production line. In the governmental context, the costs of relying on an inspection strategy as the primary means to achieve quality may be different than in commerce, but they are nonetheless real. A great deal of the delay and frustration inherent in the current OMB process is attributable to the costs of unnecessary "rework." Rework is an inevitable cost of using a system that detects problems through inspection late in the process, rather than redesigning the system to do it right the first time.

When the OMB raises fundamental issues about a rule in the final days before promulgation, after two years of agency work, agency staffers understandably scream "foul" and complain of "late hits." Moreover, from the EPA's perspective, creative options are often unavailable when issues are raised late, because, at such a late date, it is impossible to perform the necessary staff work and develop the record to support a change in approach (not to mention to comply with public notice-and-comment requirements).

The truth of the matter is that the "inspector," the OMB, has never given the "workers" in the agencies the basic tools needed to do it right the first time. While technical guidance abounds about the required contents of the technical

28. See infra text accompanying notes 37-38 for a discussion of shared and conflicting agency goals.

29. WALTON, supra note 24 , at 60 . See also AGUAYO, supra note 24 , at 139-48. 
economic analysis, the RIA, the OMB has never clearly articulated its standard of review to the political managers at the agencies. ${ }^{30}$ Agency managers are left to deduce from case-by-case experience what the OMB requires before it will sign off on a rule. Correcting a worker's errors one-by-one is an extremely inefficient and frustrating training strategy.

To his credit, Arthur Fraas, chief of the Natural Resources Branch of OIRA, at OMB, the chief reviewer of EPA rules, recognizes that improved methods of helping the agencies get it right the first time are needed. In a 1991 article, Fraas mentions hopefully several new OMB guidelines dictating improvements in the content of RIAs, but he concludes:

The new OMB guidelines and the OMB efforts under Executive Order 12291 will not be sufficient, however, to improve federal agency analysis of proposed regulatory actions. These measures will need to be supplemented by institutional changes within the agencies so that decisionmakers are provided with the analysis required to make effective and efficient regulatory decisions. ${ }^{31}$

To some degree, the promulgation of Executive Order 12,498 in 1985 was a recognition of the inadequacy of case-by-case inspection alone to improve regulatory quality. Executive Order 12,498 requires that each agency head annually submit to the Director of the OMB a draft statement of its regulatory goals and plans for the coming year. These plans are then reviewed and assembled, along with an introductory message (nominally signed by the president), as the annual Regulatory Program of the United States Government.

In theory, the annual process under Executive Order 12,498 for compiling this document might have become a productive setting in which the OMB and the agencies could reach a real consensus about their future goals and objectives. In reality, however, the process results in both sides producing massive amounts of paper, most of which is not read, or, if read, is not taken seriously.

At a recent panel discussion, the OMB's Deputy Director for Regulatory Affairs, Frank Hodsell, admitted that the Executive Order 12,498 process had not lived up to expectations. ${ }^{32}$ Although Hodsell attributed this failure primarily to the OMB's inability to devote sufficient resources to reviewing the agencies' draft plans, the reasons run far deeper. In the present adversarial climate, agencies like the EPA see themselves as having no incentive or motivation to be forthcoming in sharing information or developing plans cooperatively with the OMB. When asked to identify the various options under consideration as part of the regulatory planning process, they typically stonewall by responding in generalities or by stating that it is still too early in regulatory

30. To some degree, the absence of clear guidance for political appointees during the Bush Administration about what the OMB considered acceptable may have resulted from the Senate's refusal to confirm President Bush's nominee to head OIRA in a dispute over procedures.

31. Arthur Fraas, The Role of Economic Analysis in Shaping Environmental Policy, 54 LAW \& CONTEMP. PROBS. 125 (Autumn 1991) (emphasis added).

32. Frank Hodsell, Panel Discussion Before the ABA Administrative Law Section, Washington, D.C., October 2, 1992. 
development to identify specific options, even though the agency's work groups may already be considering several well-defined options.

As long as agencies continue to see themselves as being locked in a competitive power struggle with the OMB over the content of regulations, a struggle in which one side ultimately "wins" and the other "loses," 33 all the paper planning in the world will not lead to real improvements in the process. Agencies will continue to hide the ball, and engage in other bureaucratic stratagems, fearing that greater involvement by the OMB in the early stages of regulatory development will only increase the OMB's power to work its will to the agency's detriment.

\section{Increasing Alignment With Suppliers And Defining Quality}

The recent climate of mutual hostility and suspicion between agencies and the OMB is similar to that which has traditionally prevailed between labor and management in poorly-run enterprises. Workers, who are in the best position to be aware of problems in the production process, are afraid to suggest improvements in productivity for fear that such suggestions will lead to layoffs. ${ }^{34}$ Before workers will be willing to aid in improving the system, they must overcome their fears and see themselves as having a long-term stake in the enterprise. To this end, management must foster a common sense of mission and purpose.

One of Dr. Deming's most revolutionary ideas comes into play here. Rather than switching suppliers to take advantage of short-term cost differentials, Dr. Deming argues that enterprises should form stable relationships with suppliers, based on loyalty and trust, making them long-term partners in improving the common enterprise. ${ }^{35}$ "A buyer will serve his company best," he argues, not by striking deals with the cheapest supplier in the short run, but "by developing a long-term relationship of loyalty and trust with a single vendor" so that customer and supplier can work "together to reduce costs and improve quality." 36

Adapting this principle to the context of government is not a simple task. The EPA does not distrust the OMB because it is afraid that the OMB will take its business elsewhere. Rather, the EPA and the OMB are institutions that see themselves as committed to different values, different missions, and different conceptions of what constitutes good policy. As long as they see themselves as being locked into a competitive struggle over the content of particular rules, they will have no reason to cooperate.

One potential way to develop a more cooperative relationship between the EPA and the OMB has already been tried: internalizing the OMB-review

33. See Percival, supra note 6, at 153.

34. WALTON, supra note 24 , at 72-73.

35. AgUAYO, supra note 24, at 149-57.

36. WALTON, supra note 24 , at 62 . 
process by creating a devil's advocate within the agency. Throughout the Reagan years, the EPA's policy office, the Office of Policy, Planning and Evaluation ("OPPE"), served as a kind of "mini-OMB" within the agency. OPPE shared many of the OMB's economic perspectives and values and raised its concerns during internal agency policy deliberations before rules went to the OMB for review. ${ }^{37}$ This was a useful development, as it gave agency managers both a valuable advance look at the kinds of arguments that they would face at the OMB and an opportunity to build creative responses into rules at the agency level. Over time, however, OPPE came to be viewed as "the enemy within." During the Bush Administration, OPPE analysts were on occasion actually accused of talking to their counterparts at the OMB, a "charge" that they vehemently denied. As OPPE took on new missions in the international arena and in promoting cross-media integration, its role as an advocate for regulatory creativity and efficiency on particular rules gradually atrophied.

While bringing the culture of regulatory review inside the agency's doors is a useful first step, developing a relationship of trust and cooperation requires more fundamental changes. Deming's idea of stable, cooperative relationships between customers and suppliers depends not only upon mutual understanding and exchange of information, but also upon developing a common vision and a shared stake in the long-term goals of the enterprise. The EPA and the OMB currently lack such shared goals.

In a commercial context, workers, suppliers, and management can develop a shared sense of mission around the idea of improving quality-a common purpose for the enterprise from which all can benefit. According to Deming, quality can be defined as anything that enhances the product from the viewpoint of the customer. ${ }^{38}$ When quality is enhanced, all members of the enterprise can share the benefits. Is there any analogous lodestar for quality in government?

The first problem in applying the quality paradigm to government is determining who one's "customers" really are. Do officials of the Executive Branch owe their ultimate allegiance to the president, to the Congress, to the statutes they administer, to constituent groups, to the best interests of the citizens of the United States, or to some abstract ideals of professionalism? These are not easy issues, and they underlie a great deal of the tensions between the EPA and the OMB, particularly during the Reagan and Bush Administrations, when one party controlled the Congress and another the Presidency. Few career EPA employees believe in their heart of hearts that the temporary occupant of either the EPA Administrator's office or the White House is their ultimate "customer." Nor do they believe that giving either one whatever she or he wants necessarily translates into better quality. On the other side of the street (or, more precisely, at the other end of Pennsylvania Avenue), the OMB will never be more effective at improving regulation until it recognizes the legitimacy of the statutory missions

37. See MCGARITY, supra note 7, at 239-40.

38. AGUAYO, supra note 24 , at 35 . 
that Congress has given the agencies, missions that agency employees take seriously.

In Reinventing Rationality, an excellent book about the rise of OMB review, Professor Thomas McGarity portrays the conflict between the OMB and the EPA and other regulatory agencies as a seemingly irreconcilable clash of "two regulatory cultures" with different goals and values. ${ }^{39}$ While these problems are very real, there are two basic responses to them. First; the gulf between the EPA's goals and the OMB's goals may not actually be so wide that it is impossible to identify areas in which the two sides might agree on a vision of good policy. Second, in the same way that incentives must be created that encourage workers and suppliers to become partners in the overall enterprise, so too must the EPA and other agencies be given a stake in making their rules more efficient.

\section{$\mathrm{V}$ \\ What THE Clinton Administration SHOULd Do}

\section{A. Defining Shared Goals}

The first step in developing a more cooperative relationship between the $\mathrm{OMB}$ and the agencies would be to develop an agreed-upon statement of goals. Conflicts between the goals of the EPA and the OMB can best be accommodated if they are brought out into the open and resolved through mutual discussion, in order to identify areas of agreement and common interests. Few, if any, at the EPA actually believe that wasting economic resources is a good thing; it is simply a price that some are more willing than others to accept if necessary to achieve their overarching goal of protecting public heath and the environment. Similarly, I have never met an OMB analyst who was truly opposed to all government action to eliminate risks to health and the environment, as long as she could be convinced that the risk was real and substantial, and that the government's action would produce net benefits in excess of costs. Hence, there is room for substantial agreement in reaching a definition of quality in the context of environmental regulation.

A presidential edict, whether in the form of an Executive Order or the Annual Regulatory Message, is no substitute for a dialogue at the working level to develop an agreed-upon statement of goals by which quality can be measured. A fundamental premise of the Deming management philosophy is that simply mandating a change in objectives from the top down will not work,;0 top management must transform the system, but they can do so only by creating conditions in which everyone becomes an active participant in improving quality.

39. See generally MCGARITY, supra note 7.

40. See AGUAYO, supra note 24 , at 11-12 (criticizing "management by objectives"); Walton, supra note 24 , at $90-92$ (emphasizing the dangers of using performance ratings). 
Amazingly enough, however, dialogue between agencies aimed at reaching a statement of goals and objectives does not presently occur. The EPA recently instituted an agency-wide strategic planning process, but the OMB has not been brought into the process of developing the plans. Similarly, the Regulatory Program of the United States Government ${ }^{41}$ is largely an OMB document; while agencies may be given an opportunity to review nearly final drafts of limited portions of the document, they are not brought into the process of developing the statements of regulatory goals to nearly the same extent that they participate in other major policy initiatives, such as the State of the Union Address or the National Energy Strategy.

Nor are there more informal mechanisms for developing a consensus about regulatory goals between agency managers and the OMB reviewers. For example, in the Bush Administration, new political appointees were given a twoday orientation seminar at the White House, but no one from the OMB briefed them on the goals of the regulatory review program, much less solicited their input. Nor was there any training by experienced agency managers about past successes and failures in making rules more efficient.

At the level of career staff, the lack of communication about goals and objectives is even more profound. As a matter of practice, the EPA career staff who develop rules are generally excluded from the OMB meetings at which their work product is reviewed.

Obviously, increasing the opportunities for dialogue and communication about shared goals should be a high priority for the Clinton Administration. One frequently used way to structure and focus this dialogue is to draft a "vision statement," setting forth a consensus view of the enterprise's goals. My office at the EPA went through this exercise and found that it was a surprisingly rewarding way to think through and clarify our purpose.

\section{B. Giving Agency Officials a Stake in Regulatory Efficiency}

While there is already some room for agreement on a shared definition of quality between the OMB and agencies such as the EPA, much more can and must be done to create a real community of interest around achieving regulatory goals as efficiently as possible.

Today, the OMB's regulatory review effort relies exclusively on the "stick" of disapproval. Rules that do not meet the OMB's (often vague and subjective) minimum standards of efficiency are disapproved or delayed-unless, of course, a statutory deadline or political pressure can be mounted to force the OMB to sign off despite its objections. There are no incentives for agencies to devise more creative ways to reduce costs while still achieving their regulatory objectives. Just as a commercial enterprise must find ways to convince suppliers and workers that they will share in the profits from improvements in quality

41. See supra text accompanying note 31 for a discussion of how the Regulatory Program of the United States Government is produced. 
before they will become active partners in improving product quality, so too must the OMB find ways to enlist agencies as partners in improving the quality of rules, rather than punishing them when they fail to live up to the OMB's standards.

There are several obvious ways to use incentives to promote greater regulatory efficiency. Professional recognition is one. The Deming Prize, established in 1951 in Japan for individuals and companies, is now awarded annually in a nationally televised ceremony, ${ }^{42}$ and it is "the most prestigious award a Japanese company or industrialist can win." ${ }^{43}$ On the other hand, until recently ${ }^{44}$ no president or other high level U.S. government official had ever given special public recognition to a government employee or agency for improving the quality or efficiency of its regulatory output.

More fundamentally, agencies need to be convinced that it is in their interest to improve the quality of their rules. If, as Professor McGarity and others posit, agencies such as the EPA are primarily concerned with achieving their programmatic goals, incentives should be structured so that they will achieve more of their own goals by promulgating efficient rules. At present, the incentive structure for agencies offers no reward for developing more efficient rules (other than possibly overcoming OMB and industry opposition), and it may have just the opposite effect. Innovative regulatory approaches may serve to minimize burdens on the regulatory community, but they are often riskier and more costly for agencies to develop. If the agency itself does not share appreciably in the benefits of regulatory innovation, it will have little incentive to pioneer new approaches, rather than adhering to tried and true, if inefficient, methods of regulating. ${ }^{45}$

One unobserved advantage of the proposed regulatory budget is that by establishing a fixed ceiling on the costs of regulation over a given time period, it would give agencies a tangible incentive to make their rules more efficient. Increased efficiency would allow them to address more of the risks to health and the environment within their fixed budgets. Less radical incentives might include using the standard budgetary process to reward agencies for particularly successful regulatory initiatives. ${ }^{46}$

42. WALTON, supra note 24 , at 15 .

43. AGUAYO, supra note 24 , at 6 .

44. Since 1989, the Federal Quality Institute has administered the Presidential Award for Quality to recognize federal agencies that have implemented TQM in an exemplary manner. See Presidential Award for Quality, 1993 Application, FQI-PA92, May 1992. In addition, some agancies now have internal award programs. For instance, the EPA occasionally has honored employees with the F. Henry Habicht Award for Outstanding Leadership in TQM.

45. See generally BRIAN COOK, BUREAUCRATIC PolmTICS AND REgUlatory REFORM: The EPA AND EMISSIONS TRADING (1988).

46. The conventional budgeting process is probably slightly perverse from the perspective of promoting efficient rules, in that it tends to reward bureaucratic empire-builders for promulgating inefficient rules that require more employees to operate. 


\section{Training and Skills}

In addition to motivating employees and suppliers to develop more efficient rules, managers must equip them with the skills and tools to improve the quality of their product.

Systematic training programs for agency staff about past successes, useful techniques for making rules more efficient, and what to look for in the future might be the single most cost-effective method of improving the efficiency of agency rules. Despite a substantial agency budget for training, no spending is specifically targeted toward teaching agency program staff the skills and techniques of economic and policy analysis practiced by OMB and OPPE analysts. As long as improving the efficiency of agency rules is regarded not as part of everyone's job, but only as the special province of an adversarial group of reviewers, there will be little, if any, progress in enhancing regulatory efficiency.

Enhancing the efficiency of government regulation cannot be achieved by an OMB inspection and review process tacked on at the "end of the pipe," just as end of pipe pollution controls are often not as efficient as preventing pollution in the production process. A commercial enterprise must transform its existing culture to instill a quality ethic throughout the organization. Real change requires transforming agency cultures to build quality into rules at every stage of the process. ${ }^{47}$

\section{VI \\ CONCLUSION}

Many of the conflicts in which political actors engage are unnecessary, because our present structure for identifying options is not well-suited to seeking out mutually beneficial ("win/win") options. The relationship between the EPA and the OMB is a good example of a "game" that could be re-engineered to mutual benefit. Like rats in a maze, a husband and wife in a bad marriage, or the prisoners in the Prisoner's Dilemma, the EPA and the OMB continue to play out a struggle over options that neither of them would rationally choose if the game were restructured to maximize mutual achievement of goals.

The profound knowledge of TQM is that the human systems in which we find ourselves are not given and immutable; rather than merely play the game, we can and must reflect on improving the system that creates our incentives.

47. To their credit, former-EPA Administrator William Reilly and Deputy Administrator F. Henry Habicht instituted a broadly based program of TQM training for EPA employees. This article can be understood as a plea to extend that program to the OMB and the Executive Branch more generally. 